\title{
Electrochemical and Tribological Properties of TiSiCN Coatings in Coolant
}

\author{
Zhiwei WU ${ }^{1 *}$, Shang LI ${ }^{1}$, Fei ZHOU $^{2}$ \\ ${ }^{1}$ College of Mechanical and Electrical Engineering, Nanjing Forestry University, Nanjing 210037, China \\ ${ }^{2}$ College of Mechanical and Electrical Engineering, Nanjing University of Aeronautics and Astronautics Nanjing, 210016, China \\ crossref http://dx.doi.org/10.5755/j01.ms.25.2.19252
}

Received 11 October 2017; accepted 22 March 2018

\begin{abstract}
TiSiCN coatings were prepared using DC and RF magnetron co-sputtering system. The influence of target powers on phase structures, mechanical properties, tribological and electrochemical properties were studied. The results indicated the coatings presented an amorphous structure, and the highest microhardness of $1566.4 \mathrm{HV}$ was obtained at a target power of $200 \mathrm{~W}$. In terms of the electrochemical properties in coolant, the higher charge transfer resistance of $2.64 \times 10^{7}$ $\Omega \mathrm{cm}^{2}$ and the polarization resistance $\left(\sim 1.10 \times 10^{8} \mathrm{k} \Omega . \mathrm{cm}^{2}\right)$ were obtained at low target power, indicating a better corrosion resistance. Furthermore, the friction coefficient was $1.01 \sim 1.14$ as sliding against SUS440C balls in air. In contrast, the friction coefficient decreased to $0.45 \sim 0.58$ in coolant, and the wear mechanism changed from oxidation wear into abrasive wear.
\end{abstract}

Keywords: TiSiCN coatings, friction and wear, electrochemical properties, coolant.

\section{INTRODUCTION}

It is well-known that the TiN or TiCN coating is widely used for cutting tools, however, the low oxidation resistance (about $500{ }^{\circ} \mathrm{C}$ ) inhibits their application in highspeed machining (about $800-1200{ }^{\circ} \mathrm{C}$ ) $[1,2]$. It was found that doping silicon in TiN-based coating (eg. TiN or TiCN coating) could improve the corresponding hardness, oxidation resistance and friction behavior [3-5]. Especially, in terms of quaternary TiSiCN coating, the nanocrystallites of $\mathrm{Ti}(\mathrm{C}, \mathrm{N})$ and some amorphous phases, eg. a-Si $\mathrm{N}_{3}$, a-SiC, a-SiCN and a-C, could be formed in TiSiCN coating simultaneously, which usually combined the advantages of TiCN and TiSiN coatings. Accordingly, the influence of the preparation conditions and chemical compositions (eg. silicon or carbon content) on the microstructure and mechanical properties of the TiSiCN coating has been investigated [4-7]. For example, Ref. [8] has reported that a higher hardness of $42.9 \mathrm{GPa}$ was obtained for TiSiCN coatings as compared with TiCN coating (17.3 GPa). Ref. [7] also reported that the $\mathrm{TiSi}_{(12 \text { at.\%) }} \mathrm{CN}$ coatings presented the highest hardness of $4100 \mathrm{HV}$ as compared with $\operatorname{TiSi}_{(6}$ at.\% 8 at.\%) $\mathrm{N}$ coating ( $3700 \mathrm{HV})$, and the oxidation stability temperature for the $\mathrm{TiSi}_{(4 \text { at.\%) }} \mathrm{CN}$ coating also upped to $900{ }^{\circ} \mathrm{C}$. In addition, the influence of carbon content $(6.9-22.2$ at.\%) on microstructure and mechanical property also was discussed [6], the nanocrystallite of $\mathrm{TiN}, \mathrm{TiC}$ and $\mathrm{Ti}(\mathrm{C}, \mathrm{N})$ was formed in TiSiCN coating as well as a- $\mathrm{Si}_{3} \mathrm{~N}_{4}$, a-SiC and little a-C, the maximum hardness of $39.8 \mathrm{GPa}$ was obtained for TiSiCN coating at a carbon content of 11.9 at. $\%$.

In terms of tribological properties of TiSiCN coating, the friction behavior in air was usually improved due to the lubrication of amorphous carbon phase by graphitization. For example, with an increase in carbon content, the

\footnotetext{
${ }^{*}$ Corresponding author. Tel.: +86 25 85427674; fax: +86 2585427674 .

E-mail address: wzwlsky@163.com (Z.Wu)
}

friction coefficient of the TiSiCN coatings decreases from 0.51 to 0.16 as sliding against $\mathrm{ZrO}_{2}$ balls, which was attributed to the low shear strength of the graphitic $\mathrm{sp}^{2}$ clusters embedded in the amorphous carbon [6]. When the tribo-test was performed in water, the low fiction coefficient and wear rate also were obtained because of the lubrication of hydrated silica gel that generated from frictional oxidation of silicides [9, 10]. For example, after doping silicon into TiCN coating, the friction coefficient of TiSiCN decreased from 0.52 to 0.21 as sliding steel ball in air due to tribochemical reactions of amorphous phases [11]. In addition, Wang et al. [12] studied the effect of bias voltage on the properties of TiSiCN coating prepared using arc ion plating technique, the results indicated that the hardness of the TiSiCN coating gradually increased from 28.3 $\mathrm{GPa}$ to $38.4 \mathrm{GPa}$ as the bias voltage increased from $-20 \mathrm{~V}$ to $-100 \mathrm{~V}$, and an improving wear resistance was also observed as sliding against $\mathrm{ZrO}_{2}$ balls in seawater lubrication. Especially, for the dynamic impact tests in different condition (eg. in distilled water and in $\mathrm{NaCl}$ solution), the TiSiCN coating presented a superior performance in impact tests than TiCN coating, because the hydrodynamic and corrosion effect could accelerate coating failures and the dense structures were thus a key reason to improve their impact wear [8]. For the corrosion resistance, some Refs. [8, 13] reported that the protection for silicon oxides passivation layers could improve the corrosion resistance of coating after doping silicon into $\mathrm{TiCN}$ or $\mathrm{CrCN}$ coating. For example, the corrosion resistance of TiSiCN coating increased from $1.7 \times 10^{-3} \mathrm{M} \Omega$ to $46.2 \mathrm{M} \Omega$ in $0.6 \mathrm{~mol} \mathrm{NaCl}$ solution with increase in substrate powers densities, indicating an improving corrosion resistance [14]. In addition, the tribocorrosion properties of TiSiCN coatings have been investigated in seawater $[6,12]$, the result indicated that sliding caused a significant negative drop in OCP because the passive film was destructed by sliding behavior, and corrosion could accelerate the deterioration of materials in tribo-test. 
As tool material for the TiN-based coating, which usually subjected the wear and corrosion simultaneous in water-based coolant. Therefore, it is necessary to study the electrochemical and tribological properties of TiSiCN coatings in coolant. However, Ref. [8] has pointed out that the separate studies on friction and corrosion properties of coating was a reliable experimental method to assess either a mechanical or electrochemical effect because the tribocorrosion could result in an accelerated material degradation [15]. Thus, the tribological and electrochemical properties of TiSiCN coating were discussed in coolant separately.

\section{EXPERIMENTAL DETAILS}

\subsection{Deposition of TiSiCN coatings}

TiSiCN coatings were deposited on $316 \mathrm{~L}$ stainless steel substrate and $\mathrm{Si}$ (100) disks using DC and RF magnetron co-sputtering system (Diamant-MINI-12). The $\mathrm{Ti}$ and SiC targets with a purity of $99.9 \%$ were installed on the DC target and the RF target, respectively. In order to eliminate the interference of the gas (air, steam, etc.) in the deposition chamber, the chamber was first evacuated to $4 \times 10^{-4} \mathrm{~Pa}$, and then the substrates were cleaned with $\mathrm{Ar}$ plasma sputter generated by glow discharge at a bias voltage of $-450 \mathrm{~V}$ along with Ar flow of $16 \mathrm{sccm}$ for 10 min. A pure $\mathrm{Ti}$ interlayer was first deposited on substrates for 30 min at a DC target power of $100 \mathrm{~W}$ with a negative bias voltage of $150 \mathrm{~V}$. Usually, the $\mathrm{N}^{+}$ion energy was mainly influenced by the bias voltage. If the bias voltage was below $(<-40 \mathrm{~V})$, the coating microstructure became porous owing to the insufficient ion bombardment, while high bias voltage could lead to the coating delamination because of high inert stress. Thus, the bias voltage was set to $-150 \mathrm{~V}$. In addition, appropriate substrate heating could remove the impurities (e.g. water vapor) on the substrate and improve the adhesion between coating and substrate, thus the substrate temperature was set at $150{ }^{\circ} \mathrm{C}$. Subsequently, the TiSiCN coatings were deposited for 3 hours by adjusting RF target power $(100 \mathrm{~W}, 150 \mathrm{~W}, 200 \mathrm{~W}, 250 \mathrm{~W})$ in a mixed gas of Ar and $\mathrm{N}_{2}$ (16 and $\left.15 \mathrm{sccm}\right)$. The TiSiCN coatings were named as TiSiCN-100, TiSiCN-150, TiSiCN-200, TiSiCN-250 according to RF target power.

\subsection{Microstructure and mechanical characterization of TiSiCN coatings}

The crystal phase of TiSiCN coatings was characterized using X-ray diffractometer (XRD, Ultima IV, Japan) with CuKa radiation source $(\lambda=0.1542 \mathrm{~nm})$ at a scan rate of $5^{\circ} / \mathrm{min}$ from $20^{\circ}$ to $80^{\circ}$. The thickness of coating and element content were observed by a field emission scanning electron microscope (SEM) (JEOLJSM-7001F) equipped with EDS (Inca Energy 350, Oxford, UK). The surface roughness and depth of indentation for TiSiCN coating were measured by atomic force microscopy (AFM, Dimesion Edge, Germany) operated in semi contact (tapping) mode with a $\mathrm{Si}_{3} \mathrm{~N}_{4}$ probe. The microhardness was tested by microhardness tester (HVS-1000, china) with a $120^{\circ}$ diamond probe, a load of $9.8 \mathrm{mN}$ was applied and held for 10 seconds. And then the microhardness of the coatings was calculated automatically according to the four point measurement method. The adhesion strength of TiSiCN coatings with a thickness of about $1.2 \mu \mathrm{m}$ was measured using a scratch tester (WS-2005, Scratch Tester, China) equipped with a hemispherical diamond tip $(R=0.2 \mathrm{~mm})$. In the testing process, the applied load, sliding speed and wear track length were set as $20 \mathrm{~N}, 20 \mathrm{~N} / \mathrm{min}, 3 \mathrm{~mm}$, separately. The scratch tests were repeated for three times to obtain the average value.

\subsection{Electrochemical and tribological properties of TiSiCN coatings}

The electrochemical tests of TiSiCN coatings were performed using a standard three electrode electrochemical cell in coolant. The chemical composition of water-based cutting fluid was listed in Table 1. The TiSiCN coatings on $\mathrm{Si}$ (100) wafers were cut into $2 \mathrm{~cm}$ square specimens, after a copper wire was connected on coating by conductive carbon tape, which was enveloped by 704 silicon rubber with an exposure area of $1 \times 1 \mathrm{~cm}^{2}$. The electrochemical impendence spectroscopy (EIS) tests were tested at an AC excitation of $10 \mathrm{mV}$ over a frequency range of $1 \mathrm{mHz}$ to $100 \mathrm{kHz}$ after 1 hour of open circuit voltage (OCP) testing. Subsequently, the potentiodynamic polarization tests were performed as the voltage varied from $-1 \mathrm{~V}$ to $1 \mathrm{~V}$ at a

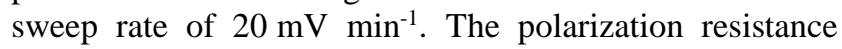
$\left(\mathrm{R}_{\mathrm{p}}\right)$ of coatings was calculated using Stern-Geary Eq. 1 [16].

$$
R_{p}=\frac{\beta_{a} \beta_{c}}{2.303 i_{\text {corr }}\left(\beta_{a}+\beta_{c}\right)},
$$

where the $\beta_{\mathrm{a}}$ and $\beta_{\mathrm{c}}$ are the Tafel anodic and cathodic slopes, the corrosion current density (icorr) was deduced by the Tafel extrapolation from the curves.

The tribo-test sliding against SUS440C balls was performed using ball-on-disk tribometer in air and in coolant, separately. The applied load, sliding speed and sliding distance were set to $2 \mathrm{~N}, 0.1 \mathrm{~m} / \mathrm{s}$ and 500 meters separately. In addition, the diameter, hardness, elastic modulus and surface roughness of SUS440C ball was $8 \mathrm{~mm}, 7.2 \mathrm{GPa}, 204 \mathrm{GPa}$ and $53.3 \mathrm{~nm}$.

Table 1. Chemical composition of water-based cutting fluid

\begin{tabular}{|c|c|}
\hline Designation & Content \\
\hline $\mathrm{H}_{2} \mathrm{O}$ & $500 \mathrm{ml}$ \\
\hline$\left(\mathrm{HOCH}_{2}\right)_{2}$ & $983.12 \mathrm{ml}$ \\
\hline $\mathrm{Na}_{2} \mathrm{~B}_{4} \mathrm{O}_{7} .10 \mathrm{H}_{2} \mathrm{O}$ & $50 \mathrm{~g}$ \\
\hline $\mathrm{Na}_{2} \mathrm{SiO}_{3} \cdot 5 \mathrm{H}_{2} \mathrm{O}$ & $16.67 \mathrm{~g}$ \\
\hline $\mathrm{Na}_{3} \mathrm{PO}_{4}$ & $3.33 \mathrm{~g}$ \\
\hline
\end{tabular}

\section{RESULTS AND DISCUSSION}

\subsection{Microstructure and mechanical characterization of $\mathrm{TiSiCN}$ coatings}

As seen in Fig. 1, only a preferred diffraction peak was obtained around $28^{\circ}$, which was the diffraction peak of silicon substrate, indicating that the TiSiCN coatings presented the amorphous structure. Table 2 shows the element concentration of TiSiCN coatings. With an 
increase of $\mathrm{SiC}$ target powers, the $\mathrm{C}$ and $\mathrm{N}$ content all showed an increasing trend. Though the content of $\mathrm{Si}$ decreased from 73.2 at.\% to 55.2 at.\%, which still kept a high concentration. As a result, there was a high content of amorphous $\mathrm{Si}_{3} \mathrm{~N}_{4}$ and $\mathrm{SiC}$ as well as free silicon in the coating, which resulted in the amorphous structure of the coating.

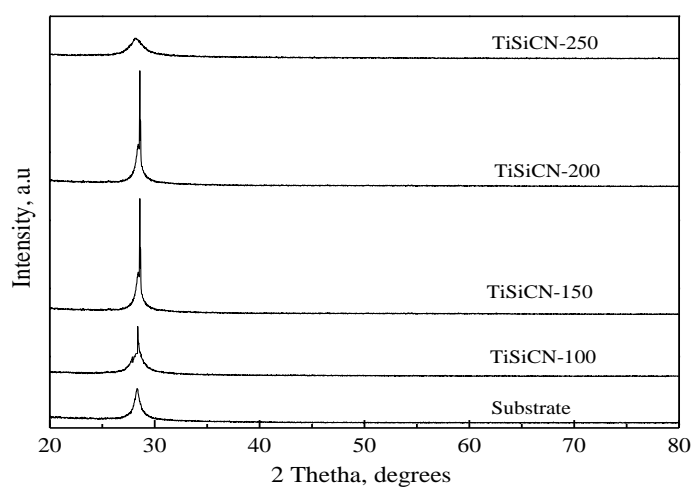

Fig. 1. XRD spectrum of TiSiCN coating

Just as shown in Fig. 2 a, the mean thickness was about $1.2 \pm 0.1 \mu \mathrm{m}$ for all TiSiCN coatings according to SEM images. The depth of indentation was about $150 \mathrm{~nm}$ according to AFM test in Fig. $2 \mathrm{~b}$, which was less than coating thickness.

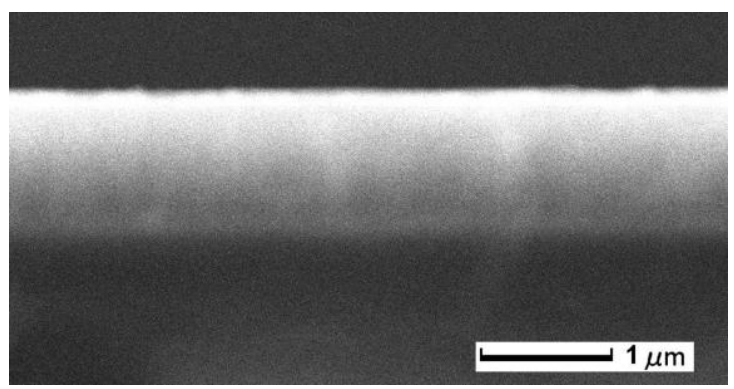

a

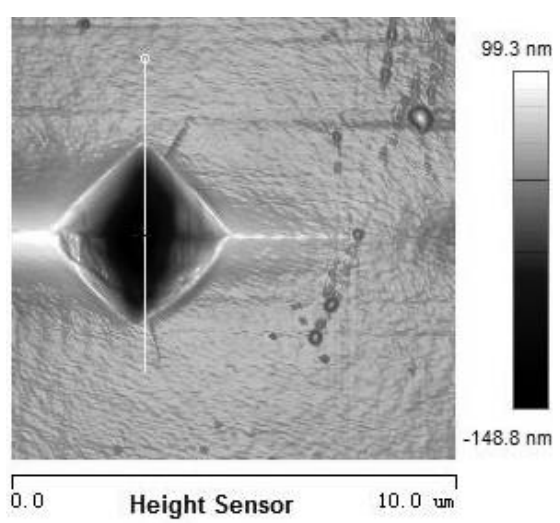

b

Fig. 2. $a-$ cross sectional image; b-depth of indentation of TiSiCN-50 coating

Thus, the substrate has little effect on coating hardness. The microhardness of the coatings gradually increased $(1152.6 \mathrm{HV} \rightarrow 1192.2 \mathrm{HV} \rightarrow 1566.4 \mathrm{HV})$ with an increase in target power from $100 \mathrm{~W}$ to $200 \mathrm{~W}$, and then decreased to $1229.2 \mathrm{HV}$ at a target power of $250 \mathrm{~W}$. The change of microhardness was related to the content of amorphous $\mathrm{Si}_{3} \mathrm{~N}_{4}$ and $\mathrm{SiC}$ phase in the coating [9-11].
When TiSiCN coating was deposited at $250 \mathrm{~W}$, the content of $\mathrm{C}$ and $\mathrm{N}$ increased to maximum value 11.7 at.\% and 13.5 at.\% separately. That result indicated more amorphous $\mathrm{Si}_{3} \mathrm{~N}_{4}$ and $\mathrm{SiC}$ phase were formed in TiSiCN250 coating, which caused a decline in hardness.

Table 2. Element concentration of TiSiCN coatings deposited at different $\mathrm{SiC}$ target powers

\begin{tabular}{|c|c|c|c|c|}
\hline Coatings & $\mathrm{Ti}$, at.\% & $\mathrm{Si}$, at. $\%$ & $\mathrm{C}$, at.\% & $\mathrm{N}$, at.\% \\
\hline TiSiCN-100 & 19.0 & 73.2 & 6.7 & 1.1 \\
\hline TiSiCN-150 & 19.9 & 67.7 & 9.2 & 3.2 \\
\hline TiSiCN-200 & 19.7 & 66.2 & 8.8 & 5.3 \\
\hline TiSiCN-250 & 19.5 & 55.2 & 11.7 & 13.5 \\
\hline
\end{tabular}

Fig.3 shows the acoustic emission (AE) signals and optical micrographs of scratches in scratch tester. The critical load was determined by the intensity of AE signals and friction force. As seen the AE signals in Fig. 3, the sudden appearance of AE signal indicated the occurrence of micro-cracks of coatings, the corresponding critical load $\left(L_{\mathrm{c} 1}\right)$ increased from $1.1 \mathrm{~N}$ to $2.8 \mathrm{~N}$ with an increase in target power. However, the low intensity of AE signals was affected by surface roughness occasionally was pointed out [17]. To observe the change of AE intensity, a sharp amplitude of AE signals appeared after a gradual increasing intensity of $\mathrm{AE}$ signals with an increase of applied loads, which indicated that the large cracks and local spalling on coatings occurred now [17]. Similarly, some it was also reported $[8,18]$ that the coating suffered a serious spalling failure in such conditions. As seen the friction force curve in Fig. 3 a, its slope changed on the corresponding critical loads of $L_{\mathrm{c} 2}$. In terms of optical micrographs of scratch in Fig. 3 e, the critical loads of $L_{\mathrm{c} 2}$ was located at the position of the coating delamination. According to friction force curves and optical micrographs of scratch in Fig. $3 \mathrm{f}$, the critical loads of $L_{\mathrm{c} 2}$ increased from $10.5 \mathrm{~N}$ to about $13 \mathrm{~N}$, which indicated that TiSiCN coatings deposited at high target powers presented a preferable adhesion strength.

\subsection{Electrochemical properties of TiSiCN coatings}

The Nyquist plots and Bode plots of TiSiCN coatings in coolant are illustrated in Fig. 4. As seen in Fig. 4 a, the incomplete capacitive reactance arcs were observed, and a larger radius of capacitive reactance arcs was obtained for TiSiCN-250 coatings, indicating a better corrosion resistance [13]. In addition, a higher modules of impedance (|Z|) was obtained for TiSiCN-250 coatings at a low frequency range $\left(10^{-3} \sim 10^{0} \mathrm{~Hz}\right)$ in Fig. $4 \mathrm{~b}$. In terms of phase angle in Fig.4c, there was not any regular changes for coatings at the low frequency range. The phase angle of TiSiCN-100 and TiSiCN-200 coating decreased at a low frequency range $\left(10^{-3} \sim 10^{0} \mathrm{~Hz}\right)$. In contrast, the phase angle of TiSiCN-250 coating increased from $20^{\circ}$ to $80^{\circ}$ at the frequency range of $10^{-3} \sim 10^{1} \mathrm{~Hz}$, indicating that which could play an ideal capacitor to prevent from electrolyte attacking in a broader frequency ranges [19]. As read in Ref. [13], the equivalent circuit (EC) for TiSiCN coatings has been described, where the annotation of the component also was explained in detail. The corresponding values of each component in EC were fitted using Zsimpwin software and listed in Table 3. 


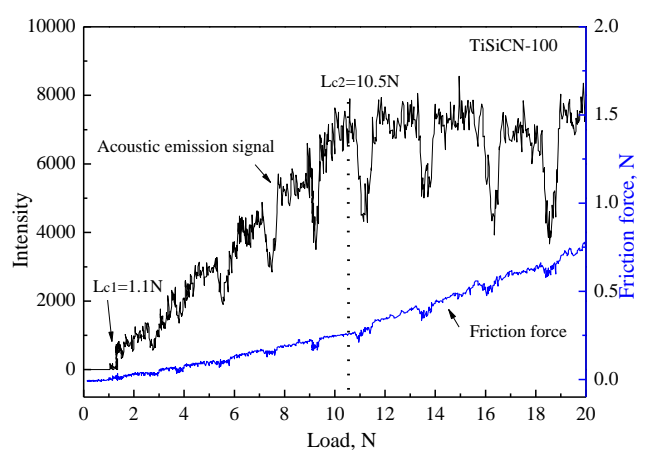

a

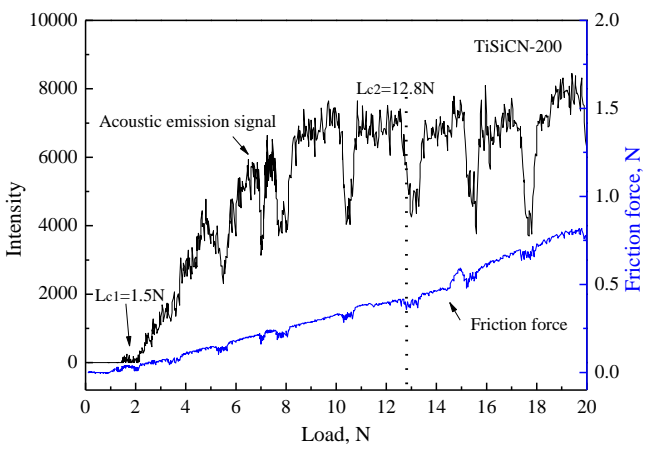

c

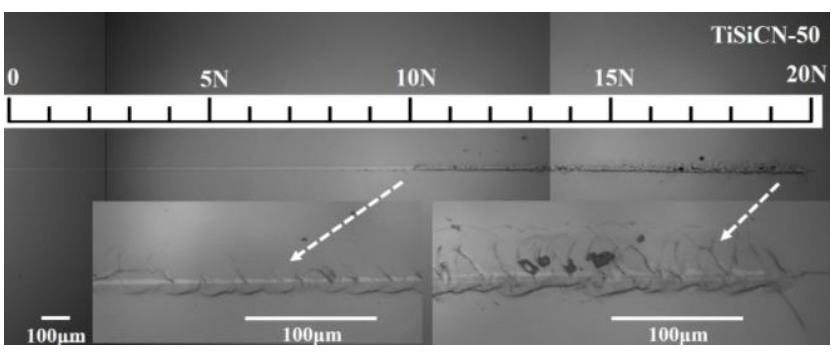

e
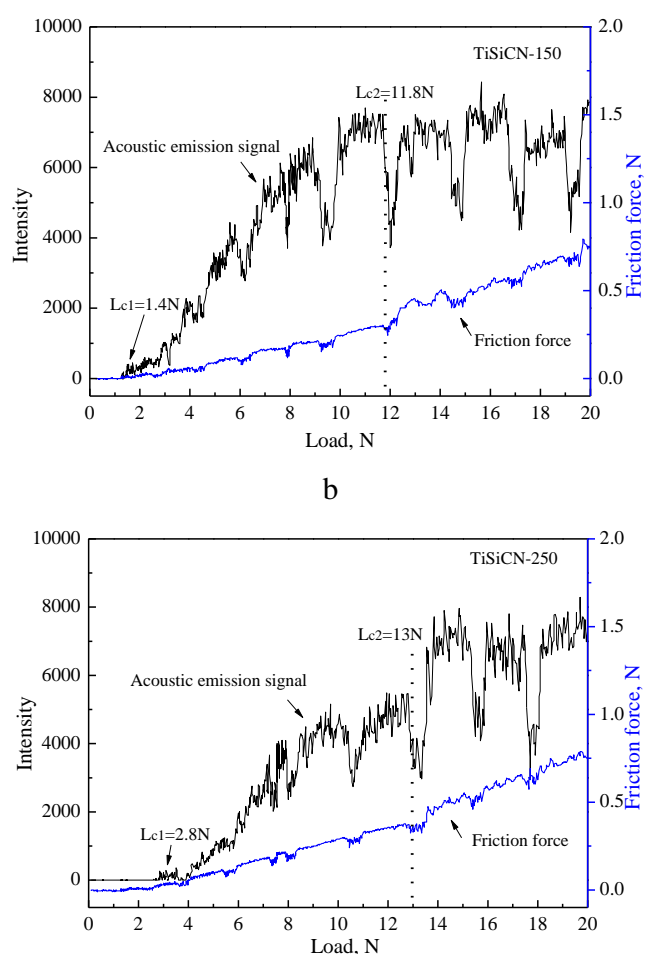

d

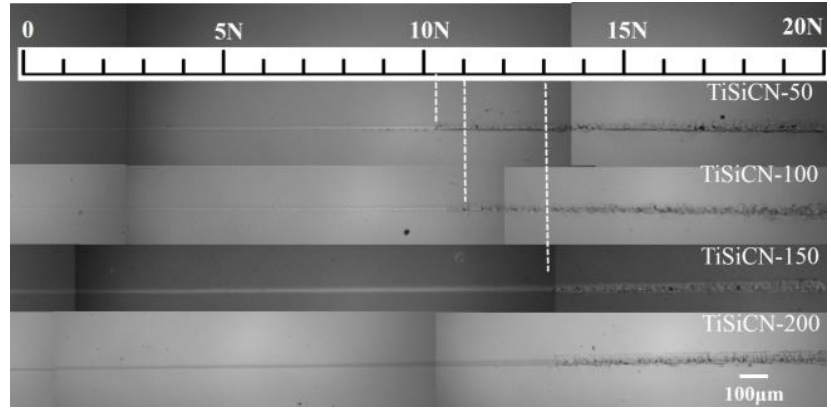

f

Fig. 3. $\mathrm{a} \sim \mathrm{d}$-acoustic emission signals; $\mathrm{e}, \mathrm{f}-$ optical micrographs of TiSiCN coatings by a scratch tester

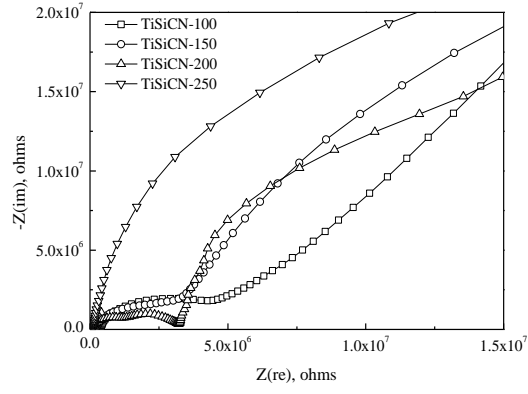

a

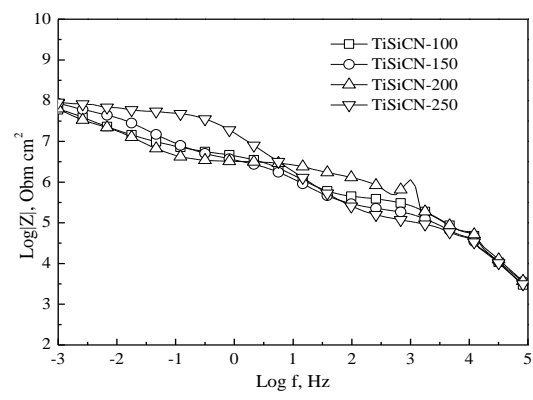

b

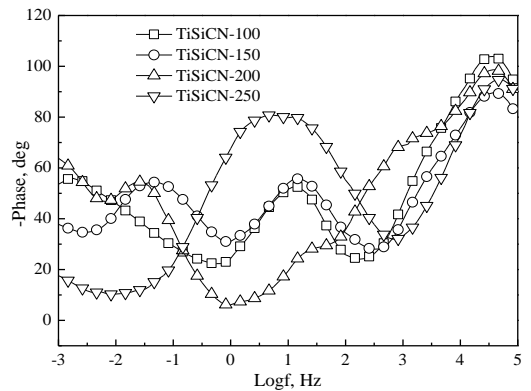

c

Fig. 4. $a-$ Nyquist plots; $b$, c-Bode plots of TiSiCN coatings in coolant

Table 3. Characteristics of the equivalent circuits derived from the EIS spectra in cutting fluid

\begin{tabular}{|c|c|c|c|c|c|c|c|}
\hline Coatings & $R_{\mathrm{s}}, \Omega \mathrm{cm}^{2}$ & $\left(\mathrm{CPE}-\mathrm{Y}_{0}\right) \mathrm{P} 0, \mathrm{~F} \mathrm{~cm}^{-2}$ & $(\mathrm{CPE}-\mathrm{n})_{\mathrm{P} 0}$ & $R_{\mathrm{po}}, \Omega \mathrm{cm}^{2}$ & $\left(\mathrm{CPE}-\mathrm{Y}_{0}\right)_{\mathrm{P} 0}, \mathrm{~F} \mathrm{~cm}^{-2}$ & $(\mathrm{CPE}-\mathrm{n})_{\mathrm{dl}}$ & $R_{\mathrm{ct}}, \Omega \mathrm{cm}{ }^{2}$ \\
\hline TiSiCN-100 & 16.80 & $6.14 \times 10^{-6}$ & 0.66 & $1.70 \times 10^{5}$ & $1.71 \times 10^{-5}$ & 0.87 & $1.31 \times 10^{7}$ \\
\hline TiSiCN-150 & 15.56 & $1.18 \times 10^{-6}$ & 0.80 & $1.77 \times 10^{5}$ & $3.51 \times 10^{-5}$ & 0.75 & $2.64 \times 10^{7}$ \\
\hline TiSiCN-200 & 15.79 & $2.27 \times 10^{-6}$ & 0.74 & $2.16 \times 10^{5}$ & $1.24 \times 10^{-5}$ & 0.77 & $1.95 \times 10^{7}$ \\
\hline TiSiCN-250 & 16.32 & $2.36 \times 10^{-7}$ & 0.96 & $5.92 \times 10^{5}$ & $8.27 \times 10^{-5}$ & 0.73 & $1.89 \times 10^{7}$ \\
\hline
\end{tabular}


The pore resistance $\left(R_{\mathrm{po}}\right)$ values increased from $1.70 \times 10^{5} \Omega \mathrm{cm}^{2}$ to $5.92 \times 10^{5} \Omega \mathrm{cm}^{2}$ with an increase in target power, thus the dense microstructure in TiSiCN coating was formed at high target power. For the charge transfer resistance $\left(R_{\mathrm{ct}}\right)$, a higher value of $2.64 \times 10^{7} \Omega \mathrm{cm}^{2}$ was obtained for TiSiCN-150 coating, indicating a better anti-corrosion ability.

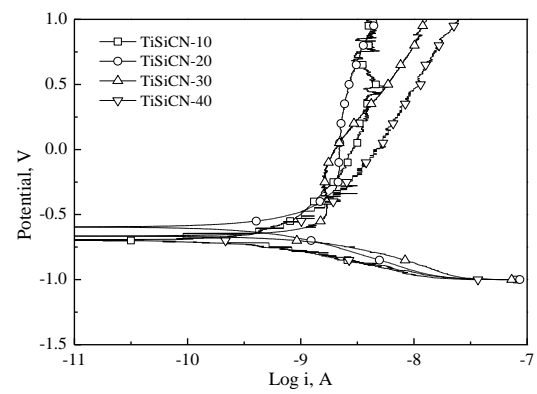

Fig. 5. Polarization curves of TiSiCN coatings in coolant

In order to evaluate the kinetic information on corrosion performance, the potentiodynamic polarization test was performed after EIS testing in coolant. The polarization curves were shown in Fig. 5, the $R_{p}$ was calculated according to Eq. 1 and listed in Table 4. The TiSiCN-100 and TiSiCN-150 coatings displayed lower corrosion current densities $\left(i_{\text {corr }}=3.71 \sim 3.73 \times 10^{-10} \mathrm{~A} / \mathrm{cm}^{2}\right)$ than other two coatings. This implied that the corrosion rates of TiSiCN-100 and TiSiCN-150 coating were lower than other two coatings during polarization process [20]. Furthermore, the higher $R_{\mathrm{p}}$ values $\left(\sim 1.1 \times 10^{8} \mathrm{k} \Omega \cdot \mathrm{cm}^{2}\right)$ also were obtained for TiSiCN-100 and TiSiCN-150 coatings, which indicated that TiSiCN-100 and TiSiCN150 coatings possessed better corrosion resistance than other two coatings. As a result, the TiSiCN coatings deposited at low target powers presented a better corrosion resistance in coolant.

Table 4. Results of potentiodynamic polarization tests

\begin{tabular}{|c|c|c|c|c|c|}
\hline Coatings & $E_{\text {corr }}, \mathrm{V}$ & $i_{\text {corr }, ~} \mathrm{~A} / \mathrm{cm}^{2}$ & $\beta_{\mathrm{a}}, \mathrm{V}$ & $\beta_{\mathrm{c}}, \mathrm{V}$ & $R_{\mathrm{p}}, \mathrm{k} \Omega \cdot \mathrm{cm}^{2}$ \\
\hline TiSiCN-100 & -0.70 & $3.71 \times 10^{-10}$ & 0.28 & 0.14 & $1.10 \times 10^{8}$ \\
\hline TiSiCN-150 & -0.60 & $3.73 \times 10^{-10}$ & 0.21 & 0.16 & $1.08 \times 10^{8}$ \\
\hline TiSiCN-200 & -0.67 & $1.17 \times 10^{-9}$ & 0.45 & 0.16 & $4.38 \times 10^{7}$ \\
\hline TiSiCN-250 & -0.68 & $8.28 \times 10^{-10}$ & 0.23 & 0.13 & $4.36 \times 10^{7}$ \\
\hline
\end{tabular}

\subsection{Tribological properties of TiSiCN coatings}

The friction behavior of TiSiCN coatings sliding against SUS440C balls in air and coolant was shown in Fig. 6. As seen in Fig. 6 a, a low friction coefficient was obtained in running-in period accompanied with a short running-in distance. That result was attributed to their low surface roughness [21]. According to AFM tests, with an increase of target powers, the average roughness $\left(R_{\mathrm{a}}\right)$ for TiSiCN coatings was $2.91 \mathrm{~nm}, 0.67 \mathrm{~nm}, 1.10 \mathrm{~nm}, 0.88 \mathrm{~nm}$, respectively. Thus, there was no obvious difference in friction coefficient within 50 meters sliding distance due to their low $R_{\mathrm{a}}$ values. The friction coefficient curves fluctuated greatly in air than that in coolant. The friction coefficient was steady at $1.01 \sim 1.07$ after running in period except for TiSiCN-150 in Fig. 6 a. In contrast, the friction coefficient decreased to $0.44 \sim 0.58$ in coolant. As seen in Fig. 6 b, with an increase in target power, the mean-steady friction coefficient increased from 1.01 to 1.14 first and then slightly decreased to 1.06 and 1.05 in air. While the lowest friction coefficient of 0.44 was obtained for TiSiCN-200 in coolant. The decreasing friction coefficient was attributed to the lubrication of sodium silicon and sodium borate in coolant. As seen in Fig. 7, the black wear tracks on TiSiCN coatings were observed as sliding against SUS440C balls in air (Fig. 7 a and $b$ ), indicating that the wear tracks were covered by tribo-layer. Similarly, also reported [10] that a large amount of iron oxide $\left(\mathrm{Fe}_{2} \mathrm{O}_{3}\right)$ adhered on the wear track of CrSiCN coatings as sliding against SUS440C balls due to the low hardness and poor coefficient of TiSiCN coatings sliding against SUS440C balls antioxidant properties of steel balls.

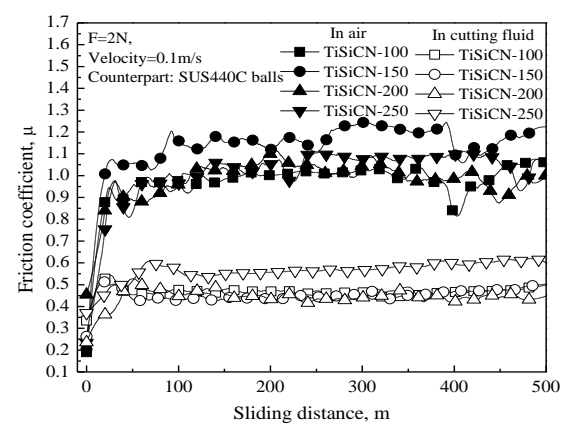

a

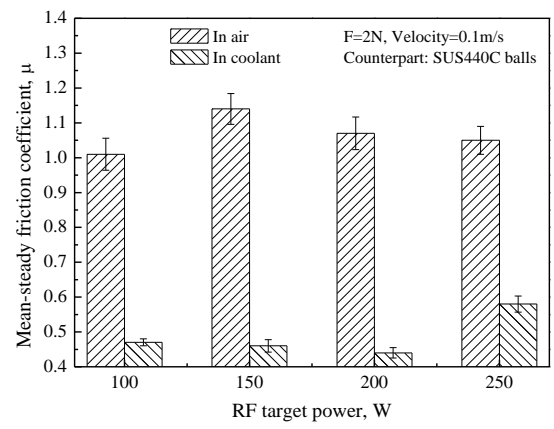

b

Fig. 6. $a$ - friction behaviour; $b$ - mean-steady friction

In that case, the iron oxide adhered to wear tacks to act as the grinding medium and then resulted in high friction coefficient. In addition, the deep scratches and large wear radius were observed on the wear scar of SUS440C ball in Fig. 7 b. Thus, the wear mechanism was dominated by mechanical wear and oxidation wear in air. In contrast, the abrasive wear scars (grooves parallel to sliding direction) were observed as testing in coolant, and the width of wear tracks also became narrowed. In addition, the radius of wear scars on SUS440C balls decreased as compared with that in air. Under the lubrication of coolant, the wear debris was easy to dissolve in coolant and lost its protective function, the titanium dioxide particles formed in friction progress to play a cutting role not only on the steel ball but also on the coatings, thus the scratches were observed on the tribopairs in Fig. $7 \mathrm{c}$ and $\mathrm{d}$. In that case, the wear mechanism changed into the abrasive wear. 


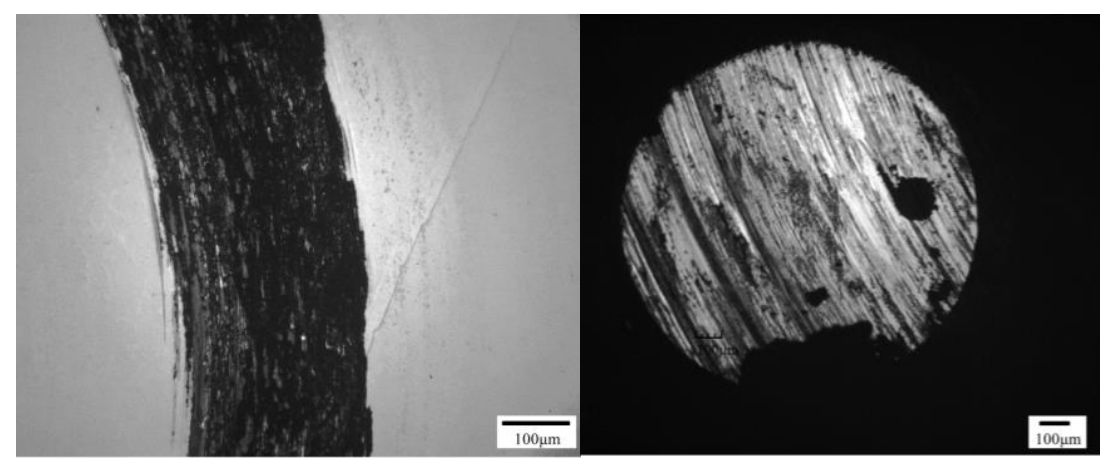

a

b

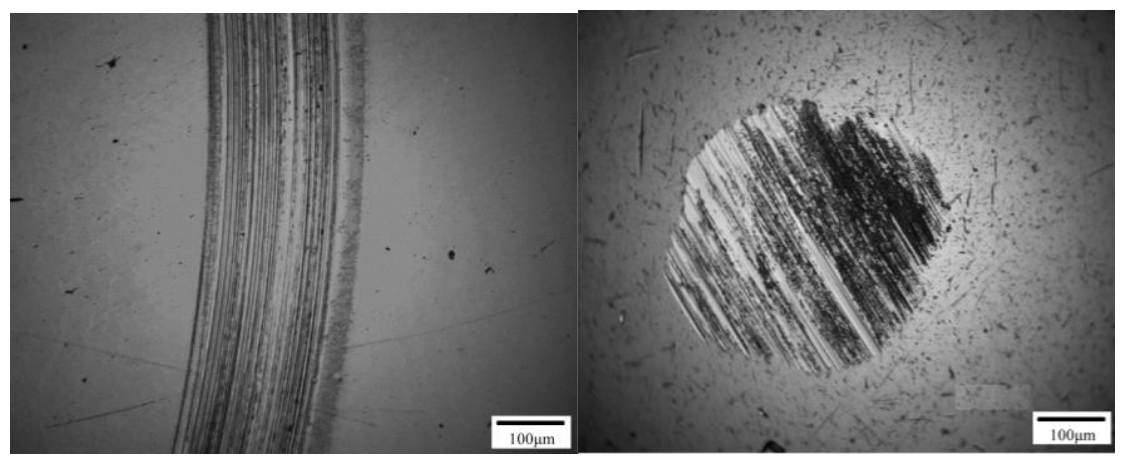

$\mathrm{c}$

d

Fig. 7. Optical photographs of wear tracks for TiSiCN/SUS440C tribopairs: a, b-TiSiCN-150/SUS440C in air; c, d-TiSiCN150/SUS440C in coolant

\section{CONCLUSIONS}

1. When the $\mathrm{SiC}$ target powers increased from $100 \mathrm{~W}$ to $250 \mathrm{~W}$, the $\mathrm{C}$ and $\mathrm{N}$ content all increased, while the $\mathrm{Si}$ element kept a high concentration (55.2 73.2 at.\%). As a result, the TiSiCN coatings presented an amorphous microstructure.

2. The highest microhardness of $1566.4 \mathrm{HV}$ was obtained for TiSiCN-200 coating. And the adhesion strength of coatings was improved with an increase of target power.

3. For the influence of lubrication conditions, the friction coefficient decreased from $1.01 \sim 1.14$ in air to $0.45 \sim 0.58$ in coolant, and the wear mechanism also changed from oxidation wear to abrasive wear.

4. The high $R_{\mathrm{ct}}$ and $R_{\mathrm{p}}$ values were obtained for TiSiCN150 coating, indicating a better anti-corrosion ability in coolant.

\section{Acknowledgments}

This work was supported by National Natural Science Foundation of China (Grant No. 51375231), Jiangsu province college students practice and innovation training plan (201710298010Z). We would like to acknowledge them for their financial support.

\section{REFERENCES}

1. Hsieh, J.H., Tan, A.L.K., Zeng, X.T. Oxidation And Wear Behaviors of Ti-Based Thin Films Surface and Coating Technology 201 2006: pp. 4094-4098. https://doi.org/10.1016/j.surfcoat.2006.08.026
2. Özel, T., Altan, T. Process Simulation Using Finite Element Method-Prediction of Cutting Forces, Tool Stresses and Temperatures in High-Speed Flat End Milling International Journal of Machine Tools and Manufacture 40 2000: pp. $713-738$.

https://doi.org/10.1016/S0890-6955(99)00080-2

3. Xu, H., Nie, X., Wei, R. Tribological Behavior of a TiSiCN Coating Tested in Air and Coolant Surface and Coating Technolgy 20 2006: pp. 4236-4241. https://doi.org/10.1016/j.surfcoat.2006.08.066

4. Eriksson, A.O., Ghafoor, N., Jensen, J., Näslund, L-Å., Johansson, M.P., Sjölen, J., Odén, M., Hultman, L., Rosen, J. Arc Deposition of Ti-Si-C-N Thin Films from Binary and Ternary Cathodes-comparing Sources of C Surface and Coating Technology 213 2012: pp. 145-154. https://doi.org/10.1016/j.surfcoat.2012.10.038

5. Ma, S. L., Ma, D.Y., Guo, Y., Xu, B., Wu, G.Z., Xu, K.W., Chu, P.K. Synthesis and Characterization of Super Hard, Self-lubricating Ti-Si-C-N Nanocomposite Coatings Acta Materrialia 55 2007: pp. 6350-6355. https://doi.org/10.1016/j.actamat.2007.07.046

6. Wei, R.H. Plasma Enhanced Magnetron Sputter Deposition of Ti-Si-C-N Based Nanocomposite Coatings Surface and Coating Technology 203 2008: pp. 538-544. https://doi.org/10.1016/j.surfcoat.2008.05.019

7. Wang, Y., Li, J.L., Dang, C.Q., Wang, Y.X., Zhu, Y.J. Influence of Carbon Contents on the Structure and Tribocorrosion Properties of TiSiCN Coatings on Ti6Al4V Tribology International 109 2017: pp. 285-296. https://doi.org/10.1016/j.triboint.2017.01.002

8. Endler, I., Höhn, M., Schmidt, J., Scholz, S., Herrmann, M., Knaut, M. Ternary and Quarternary TiSiN and TiSiCN Nanocomposite Coatings Obtained by Chemical Vapor Deposition Surface and Coating Technology 215 2013: pp. $133-140$ 
https://doi.org/10.1016/j.surfcoat.2012.10.067

9. Kuptsov, K.A., Kiryukhantsev-Korneev, P.V., Sheveyko, A.N., Shtansky, D.V. Comparative Study of Electrochemical and Impact Wear Behavior of TiCN, TiSiCN, TiCrSiCN, and TiAlSiCN Coatings Surface and Coating Technology 216 2013: pp. 273-281. https://doi.org/10.1016/j.surfcoat.2012.11.058

10. Wu, Z.W., Zhou, F., Wang, Q.Z., Zhou, Z.F., Yan, J.W., Li, L.K. Influence of Trimethylsilane Flow on the Microstructure, Mechanical and Tribological Properties of CrSiCN Coatings in Water Lubrication Applied Surface Science 355 2015: pp. 516-530. https://doi.org/10.1016/j.apsusc.2015.07.146

11. Wu, Z.W., Zhou, F., Chen, K.M., Wang, Q.Z., Zhou, Z.F., Yan, J.W., Li, L.K. Friction and Wear Properties of CrSiCN Coatings with Low Carbon Content as Sliding against $\mathrm{SiC}$ and Steel Balls in Water Tribology International 94 2016: pp. 176-186. https://doi.org/10.1016/j.triboint.2015.08.032

12. Abraham, S., Choi, E.Y., Kang, N., Kim, K. H. Microstructure and Mechanical Properties of Ti-Si-C-N Films Synthesized by Plasma-enhanced Chemical Vapor Deposition Surface and Coating Technology 202 2007: pp. $915-919$. https://doi.org/10.1016/j.surfcoat.2007.05.073

13. Wang, Y., Li, J., Dang, C., Wang, Y., Zhu, Y. Influence of Bias Voltage on Structure and Tribocorrosion Properties of TiSiCN Coating in Artificial Seawater Materials Characterization 127 2017: pp. 198-208. https://doi.org/10.1016/j.matchar.2017.03.012

14. Wu, Z.W., Zhou, F., Ma, Q., Wang, Q.Z., Zhou, Z.F., Li, L.K. Tribological and Electrochemical Properties of CrSi-C-N Coatings in Artificial Sseawater RSC Advances 6 2016: pp. 76724-76735. http://dx.doi.org/10.1039/C6RA19243B

15. El-Rahman, A.M.A., Wei, R.H. Effect of Ion Bombardment on Structural, Mechanical, Erosion and
Corrosion Properties of Ti-Si-C-N Nanocomposite Coatings Surface and Coating Technology 258 2014: pp. 320-328. https://doi.org/10.1016/j.surfcoat.2014.09.006

16. Mischler, S. Triboelectrochemical Techniques and Interpretation Methods in Tribocorrosion: A Comparative Evaluation Tribology International 41 2008: pp. $573-583$. https://doi.org/10.1016/j.triboint.2007.11.003

17. McCafferty, E. Validation of Corrosion Rates Measured by the Tafel Extrapolation Method Corrosion Science 47 2005: pp. 3202-3215. https://doi.org/10.1016/j.corsci.2005.05.046

18. Hua, M., Yuan, Z. Experiment and Evaluation of Coalescent Properties of Some Special Film-substrate Systems by Scratching Method Analysis and Testing Technology and Instruments 8 2002: pp. 218-225 (in Chinese).

19. Wu, Z.W., Zhou, F., Chen, K.M, Wang, Q.Z., Zhou, Z.F., Yan, J.W., Li, L.K. Microstructure, Mechanical and Tribological Properties of $\mathrm{CrSiC}$ Coatings Sliding against $\mathrm{SiC}$ and $\mathrm{Al}_{2} \mathrm{O}_{3}$ Balls in Water Applied Surface Science 368 2016: pp. 129-139. https://doi.org/10.1016/j.apsusc.2016.01.276

20. Wang, Q.Z., Zhou, F., Zhou, Z.F., Li, L.K., Yan, J.W. Influence of Carbon Concentration on the Electrochemical Behavior of $\mathrm{CrCN}$ Coatings in Simulated Body Fluid Surface \& Coatings Technology 265 2015: pp. 16-23. http://dx.doi.org/10.1016/j.surfcoat.2015.01.068

21. Wang, Q.Z., Zhou, F., Ding, X.D., Zhou, Z.F., Wang, C.D., Zhang, W.J., Li, L.K., Lee, S.T. Microstructure and Water-lubricated Friction and Wear Properties of $\mathrm{CrN}(\mathrm{C})$ Coatings with Different Carbon Contents Applied Surface Science 268 2013: pp. $579-587$. http://dx.doi.org/10.1016/j.apsusc.2013.01.027 